RESEARCH REPORT

\title{
Organisational downsizing and work stress: testing synergistic health effects in employed men and women
}

\author{
Nico Dragano, Pablo Emilio Verde, Johannes Siegrist
}

J Epidemiol Community Health 2005;59:694-699. doi: 10.1136/jech.2005.035089

See end of article for authors' affiliations

.....................

Correspondence to: N Dragano, Department of Medical Sociology University of Duesseldorf PO Box 101007 D-40001 Duesseldorf, Germany; dragano@ uni-duesseldort.de

Accepted for publication 30 March 2005

\begin{abstract}
Study objective: To systematically study the separate and combined effects of organisational downsizing and work related stress on a measure of health in "survivors of layoffs".

Design: Using Rothman's approach, separate and combined effects of the two exposures in estimating the risk of poor self rated health (work related symptoms) are analysed in a large sample of male and female employees.

Setting: $0.1 \%$ cross sectional sample of the German working population.

Participants: 12240 men and 10319 women, aged 16 to 59 years, surveyed in 1998-1999.

Main results: Compared with the reference group, the group of participants who were simultaneously exposed to downsizing and work related stress (effort-reward imbalance) exhibited odds ratios (OR) of three or more work related symptoms that were by far higher (OR 4.41 in men and OR 5.37 in women) than those associated with single exposures. Altogether $21 \%$ (men) and $31 \%$ (women) of the effect size of the combined exposure was attributable to synergistic interaction.

Conclusion: Although reduced health associated with organisational downsizing is partly attributable to an increase in work related stress these findings show an additional synergy effect produced by the combined exposure to both conditions.
\end{abstract}

stressful experience results from a mismatch between high efforts spent and low rewards received in turn at work, where rewards are defined in terms of money, esteem, and promotion prospects. High cost/low gain conditions reflecting lack of contractual reciprocity at work are comparatively frequent among employees who have no choice of alternative work place or who are exposed to heavy competition. Health adverse effects of effort-reward imbalance at work were reported in a number of epidemiological investigations, and were supplemented by evidence from experimental and "naturalistic" studies. ${ }^{1617}$

\section{METHODS}

\section{Participants and data collection}

This study is based on data from the 1998-1999 wave of a regularly conducted survey by the Federal Institute of Vocational Training and the Institute for Employment Research, comprising an $0.1 \%$ random sample of the German workforce. ${ }^{18}$ The response rate was $61 \%$, corresponding to a sample size of 34343 men and women aged 16 to 85 years. We restrict the current sample to the age group 16 to 59 years to reduce retirement related selection bias in older working people. Moreover, respondents had to be employed at their current work place for at least two years to be eligible for potential experience of downsizing over the past two years. Finally, we excluded self employed people as well as civil servants, given their special legal status. These restrictions resulted in a sample of 22559 participants, 12240 men and 10319 women.

Data were collected by standardised questionnaires, administered by trained interviewers in a face to face interview at the home of the participants. Important topics of the questionnaire were job history and vocational training, but aspects of the current work environment were also included. In addition, a list of symptoms and complaints that are often experienced in association with work was assessed.
In this analysis, stressful work is defined according to the model of effort-reward imbalance. ${ }^{15}$ This model claims that 
Assessment of downsizing and work related stress

In this survey, the original measurement of effort-reward imbalance was not available. ${ }^{15}$ To measure its extrinsic components "effort" and "reward", proxy measures were developed from the available list of self reported work characteristics. Eight items with closest resemblance to the original items of the scale effort were selected (sample questions: "How frequent do you work under time pressure?" "How frequent do you have to work extra hours?"). Similarly, seven items measuring reward at work were included, dealing with salary, promotion prospects and coworker support (sample questions: "How satisfied are you with your opportunities for further training?" "How satisfied are you with your salary/income?"). Response scales for all questions were dichotomised, and two unidimensional scales were constructed (internal consistencies of the scales effort and reward were $\alpha=0.70$ and $\alpha=0.67$ ). Factor loadings of the items based on exploratory principal component analysis ranged from 0.48 to 0.69 . According to the theoretical notion, a ratio of the two sum scales was generated to estimate the effect of high effort in combination with low reward..$^{15}$ Scores in the upper quartile of the ratio were defined as exposure to stressful work in terms of this model.

Two items were used to measure downsizing, the question of whether during the past two years a reduction of staff or layoff took place in the respondent's company, and the question whether the respondent's own work situation was affected by this event. Exposure to downsizing was defined as simultaneous occurrence of both conditions.

Instead of introducing the two exposure variables downsizing and effort-reward imbalance separately into a regression model and to study their interaction by a product term, a composite variable was constructed to test different combinations of exposures. This procedure was originally proposed by Rothman ${ }^{19}$ and was subsequently applied in occupational epidemiology. ${ }^{20}$ To this end, the two dichotomised exposure variables work related stress (upper quartile compared with remaining categories), and downsizing (yes/no), were combined in the following way: (1) neither downsizing, nor work stress present, (2) downsizing present, but work stress absent, (3) work stress present, but downsizing absent, (4) both downsizing and work stress present (see statistical analysis).

\section{Health measure}

Work related symptoms were assessed using a 20 item checklist. The list was compiled by a panel of occupational health experts, based on psychometrically validated questionnaires. ${ }^{21-23}$ Items included musculoskeletal pain, sleep disorders, depressed mood, breathlessness, skin irritation, and highly prevalent psychosomatic symptoms. Participants were asked to evaluate whether, and to what extent, symptoms were experienced in association with their work situation-that is, during or after work. Rather than focusing on single complaints, a sum score of symptom load was calculated (Cronbach's $\alpha=0.76$ ). A threshold of three or more symptoms was chosen to define a group of participants experiencing reduced self reported health.

\section{Covariates}

The following covariates were included: participants' socioeconomic status was defined by level of education and occupational category. Highest educational degree was categorised into three groups according to the International Standard Classification of Education": (1) "no degree or lower secondary", (2) "upper secondary",(3) "post-secondary or tertiary". Occupational category was divided into "blue collar" and "white collar" employment. Furthermore, two composite variables of a health adverse physical and chemical work environment were defined, based on a series of Likert scaled items, (1) physically demanding work (heavy lifting, vibrations, stressful posture; Cronbach's $\alpha=0.73$ ), and (2) occupational hazards (noise, heat or cold, dust, smoke, gases,

Table 1 Demographic characteristics of the participants by sex and downsizing status

\begin{tabular}{|c|c|c|c|c|c|c|c|c|}
\hline & \multicolumn{4}{|c|}{ Men $(n=12240)$} & \multicolumn{4}{|c|}{ Women $(n=10319)$} \\
\hline & \multirow[b]{2}{*}{ Number* } & \multirow[b]{2}{*}{$\%$} & \multicolumn{2}{|c|}{ Downsizing } & \multirow[b]{2}{*}{ Number ${ }^{*}$} & \multirow[b]{2}{*}{$\%$} & \multicolumn{2}{|c|}{ Downsizing } \\
\hline & & & No (\%) & Yes (\%) & & & No $(\%)$ & Yes (\%) \\
\hline \multicolumn{9}{|l|}{ Downsizing } \\
\hline No & 10495 & 85.7 & & & 9058 & 87.8 & & \\
\hline Yes & 1725 & 14.1 & & & 1246 & 12.1 & & \\
\hline \multicolumn{9}{|l|}{ Age group (years) } \\
\hline $15-29$ & 1900 & 15.5 & 16.4 & 10.5 & 1795 & 17.4 & 18.1 & 12.4 \\
\hline $30-39$ & 4335 & 35.5 & 35.7 & 34.4 & 3394 & 32.9 & 33.1 & 31.8 \\
\hline $40-49$ & 3583 & 29.3 & 29.0 & 31.5 & 3204 & 31.1 & 30.6 & 34.7 \\
\hline $50-59$ & 2402 & 19.7 & 19.0 & 23.6 & 1911 & 18.5 & 18.2 & 21.1 \\
\hline $\begin{array}{l}\text { p value } \leqslant \\
\text { Residency }\end{array}$ & 2402 & & & 0.001 & & & & 0.001 \\
\hline West Germany & 10070 & 82.4 & 83.0 & 79.1 & 8090 & 78.4 & 78.9 & 75.4 \\
\hline East Germany & 2150 & 17.6 & 17.0 & 20.9 & 2214 & 21.5 & 21.1 & 24.6 \\
\hline \multirow{2}{*}{\multicolumn{9}{|c|}{$\begin{array}{l}\mathrm{p} \text { value } \leqslant \\
\text { Education }\end{array}$}} \\
\hline & & & & & & & & \\
\hline Lower secondary & 1165 & 9.5 & 9.8 & 8.0 & 1184 & 11.5 & 11.9 & 8.4 \\
\hline Upper secondary & 7116 & 58.2 & 58.9 & 54.0 & 6409 & 62.2 & 62.4 & 60.7 \\
\hline Post-secondary and tertiary & 3939 & 32.2 & 31.3 & 38.0 & 2710 & 26.3 & 25.7 & 30.9 \\
\hline $\mathrm{p}$ value $\leqslant$ & & & & 0.001 & & & & 0.001 \\
\hline \multicolumn{9}{|l|}{ Occupational status } \\
\hline Blue collar & 5844 & 47.8 & 48.1 & 46.0 & 1670 & 16.2 & 16.6 & 13.2 \\
\hline White collar & 6376 & 52.2 & 51.9 & 54.0 & 8634 & 83.8 & 83.4 & 86.8 \\
\hline$p$ value $\leqslant$ & & & & 0.107 & & & & 0.002 \\
\hline \multicolumn{9}{|l|}{ Effort-reward imbalance } \\
\hline Low (1-3 quartile) & 9078 & 74.5 & 78.2 & 52.1 & 7767 & 75.7 & 79.4 & 49.2 \\
\hline High (4 quartile) & 3109 & 25.5 & 21.8 & 47.9 & 2490 & 24.3 & 20.6 & 50.8 \\
\hline $\mathrm{p}$ value $\leqslant$ & & & & 0.001 & & & & 0.002 \\
\hline
\end{tabular}

The $p$ values in bold type are below 0.004 (Bonferoni adjustment); all $p$ values result from Pearson's $\chi^{2}$ test. *Number of cases varies slightly because of item nonresponse $(0.2 \%-0.6 \%$ per item). 
Table 2 Percentages of participants with three and more symptoms by categories of the combined exposure variable

\begin{tabular}{|c|c|c|c|c|c|c|}
\hline & \multicolumn{3}{|l|}{ Men } & \multicolumn{3}{|l|}{ Women } \\
\hline & \multirow[b]{2}{*}{ Number } & \multicolumn{2}{|c|}{$\begin{array}{l}\text { Participants with three } \\
\text { and more symptoms }\end{array}$} & \multirow[b]{2}{*}{ Number } & \multicolumn{2}{|c|}{$\begin{array}{l}\text { Participants with three and more } \\
\text { symptoms }\end{array}$} \\
\hline & & $\begin{array}{l}\text { Number } \\
n=3724\end{array}$ & $\%(31.1)$ & & $\begin{array}{l}\text { Number } \\
n=3372\end{array}$ & $\%(33.4)$ \\
\hline \multicolumn{7}{|c|}{ Combined exposure downsizing/work stress } \\
\hline $\begin{array}{l}\text { No downsizing } \\
\text { No work stress }\end{array}$ & 8012 & 1819 & 22.7 & 7028 & 1721 & 24.5 \\
\hline $\begin{array}{l}\text { Yes downsizing } \\
\text { No work stress }\end{array}$ & 879 & 296 & 33.7 & 603 & 232 & 38.5 \\
\hline $\begin{array}{l}\text { No downsizing } \\
\text { Yes work stress }\end{array}$ & 2253 & 1115 & 49.5 & 1841 & 990 & 53.8 \\
\hline $\begin{array}{l}\text { Yes downsizing } \\
\text { Yes work stress }\end{array}$ & 821 & 494 & 60.2 & 627 & 429 & 68.4 \\
\hline$p$ value $\leqslant$ & & & 0.001 & & & 0.001 \\
\hline
\end{tabular}

toxic substances; Cronbach's $\alpha=0.83$ ). Additional work characteristics were number of weekly working hours and job insecurity (probability of losing own job). Finally, economic-regional context of downsizing was included by distinguishing between residency of participants in Eastern or Western Germany.

\section{Statistical analysis}

Firstly, bivariate analyses were conducted to test the relation between downsizing and work related stress as well as the relation between the combined exposure variable and work related symptoms, using Pearsons's $\chi^{2}$ (adjusted for multiple testing by the Bonferoni method). Then multivariate logistic regression models were fitted, calculating odds ratios (OR) and $95 \%$ confidence intervals (95\% CI) for different levels of covariate adjustment. Model 1 displays crude effects, whereas model 2 is adjusted for socioeconomic status and age. In model 3, physical and chemical exposures and working time are additionally included, whereas model 4 contains all covariates. As an increasing body of evidence suggests a sex specific effect of stressful work on health men and women were analysed separately. ${ }^{25}{ }^{26}$ Calculations were done with the statistical package SPSS 12.0.1.
The combined effect of downsizing and work stress was evaluated by applying two indices proposed by Rothman. ${ }^{19}$ With the synergy index $\left(\mathrm{S}_{\mathrm{AB}}\right)$ the degree of synergy exerted on health by the two exposures was estimated. The respective formula is:

$$
\mathrm{S}_{\mathrm{AB}}=\frac{\left(\mathrm{OR}_{\mathrm{AB}}-1\right)}{\left(\mathrm{OR}_{\mathrm{A}}+\mathrm{OR}_{\mathrm{B}}\right)-2}
$$

$\mathrm{OR}_{\mathrm{AB}}$ is the odds ratio of the joint exposure group, $\mathrm{OR}_{\mathrm{A}}$ and $\mathrm{OR}_{\mathrm{B}}$ are effect measures of the separate exposure to downsizing or work stress respectively. In each case, the reference group is composed by jointly unexposed participants. A synergy index of 1.0 implies perfect additivity and a $\mathrm{S}_{\mathrm{AB}}>\mathrm{l}$ indicates a synergistic interaction. Significance of trend was tested by calculating 95\% CI according to Hosmer and Lemeshow. ${ }^{27}$ As they rely on the $\mathrm{S}_{\mathrm{AB}}$ in a logarithmic scale, they indicate significance if 0 is not covered by the CI.

Secondly, a formula was applied that estimates the proportion of the effect that is attributable to the interaction of the two exposures $\left(\mathrm{AP}_{\mathrm{AB}}\right)$ :

Table 3 Combined exposure to downsizing and work stress in relation to work related symptoms. Multivariate logistic regression, odds ratios and $95 \%$ confidence intervals.

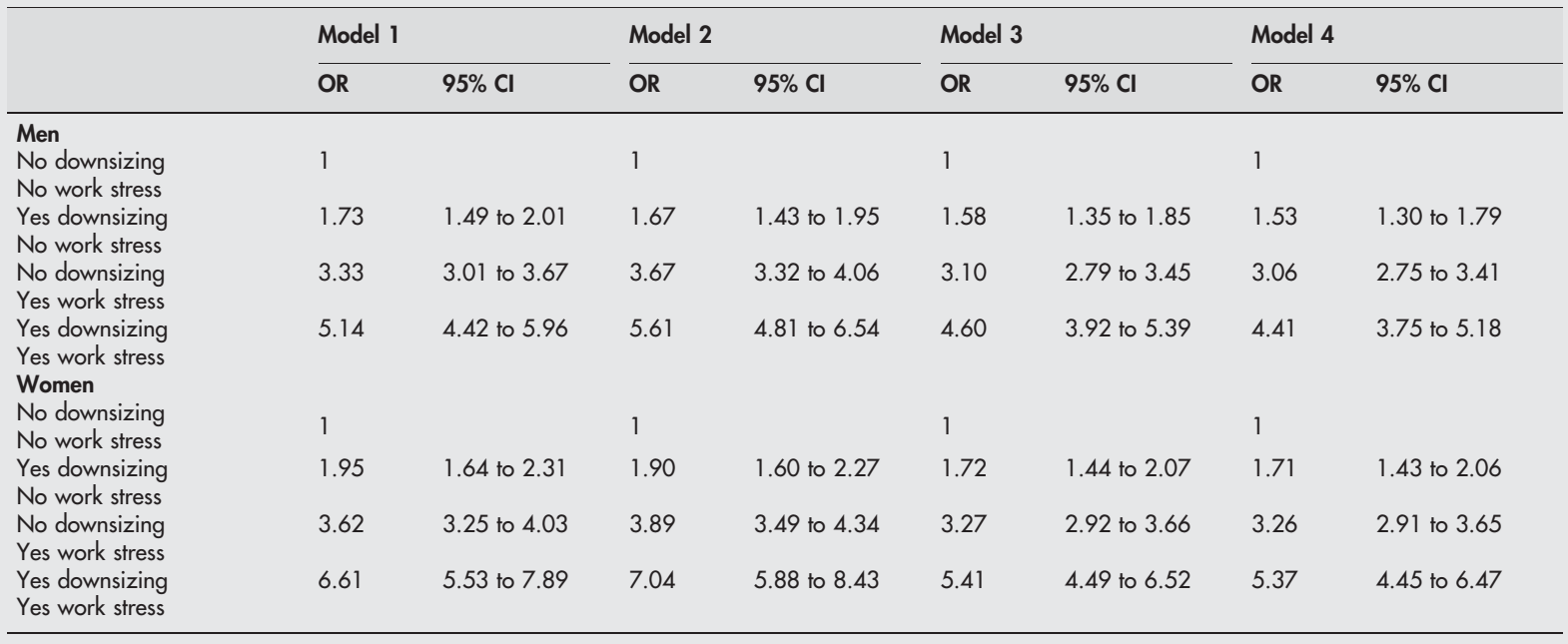

Model 1, unadjusted; model 2, adjusted for age, east/west residency, education, occupational status; model 3, adjusted for age, east/west residency, education, occupational status, physical demands and occupational hazards, weekly working hours; model 4, adjusted for age, east/west residency, education, occupational status, physical demands and occupational hazards, weekly working hours, job insecurity. 


$$
\mathrm{AP}_{\mathrm{AB}}=\frac{\mathrm{OR}_{\mathrm{AB}}-\mathrm{OR}_{\mathrm{A}}-\mathrm{OR}_{\mathrm{B}}+1}{\mathrm{OR}_{\mathrm{AB}}}
$$

According to established procedures, these measures are derived from unadjusted odds ratios of the combined exposure variable. ${ }^{28}$ To exclude possible influence by an uncontrolled bias produced by covariates, we additionally conducted analyses based on odds ratios of the fully adjusted regression model (see below, table 4).

\section{RESULTS}

In the sample $14.1 \%$ of men and $12.1 \%$ of women reported having experienced downsizing during the past two years (table 1). The proportion of survivors of lay offs varies according to age (more downsizing in older employees), residency (more downsizing in East Germany), and socioeconomic status (more downsizing in higher positions). This latter finding may reflect the fact that better educated people have a higher probability of surviving downsizing than lower skilled employees who run a higher risk of losing their job or being offered a short term contract. Moreover, work stress in terms of effort-reward imbalance is more frequent among those who experienced downsizing.

In table 2 the percentage of employees with three or more work related symptoms is given according to the four categories of the combined exposure variable. The proportion of those reporting symptoms is almost three times as large in the group with combined exposure, compared with the nonexposed group, both in men and women.

Next, multivariate analysis is performed to estimate the odds ratios of symptom load according to exposure status, with stepwise control of covariates. Results displayed in table 3 show a consistent increase in odds ratios according to exposure status both in men and women. Adjusting for confounder effects results in a minor decrease of effect size, but all effects remain statistically significant. Concerning separate effects, effort-reward imbalance is always more strongly associated with symptom load than downsizing. Yet, considerably increased odds ratios are seen in the combined exposure groups, with odds ratios of 4.4 in men and 5.4 in women in the fully adjusted model.

Finally, results of testing the synergy effect on symptom load produced by combined exposure are given in table 4 . Values $>1.0$ of the synergy index indicate that the combined exposure results in an effect that exceeds additivity. This effect is slightly stronger in women (1.57) than in men (1.35). Some $21 \%$ of the effect size (odds ratio) of combined exposure is attributable to synergy in men, whereas in women, the respective percentage is $30.9 \%$ (unadjusted odds

\begin{tabular}{|c|c|c|c|}
\hline & $\begin{array}{l}\text { Percentage of } \\
\text { association attributable } \\
\text { to interaction in the } \\
\text { joint exposure } \\
\text { group }\left(\mathrm{AP}_{\mathrm{AB}}\right)\end{array}$ & $\begin{array}{l}\text { Synergy } \\
\text { index } \\
\left(S_{A B}\right)\end{array}$ & $\begin{array}{l}95 \% \mathrm{Cl} \text { of } \log \\
\mathrm{S}_{A B}\end{array}$ \\
\hline \multicolumn{4}{|l|}{$\begin{array}{l}\text { Unadjusted ORs } \\
\text { (model I) }\end{array}$} \\
\hline Men & 21.0 & 1.35 & 0.04 to 0.56 \\
\hline $\begin{array}{l}\text { Women } \\
\text { Adjusted ORs } \\
\text { (model 4) }\end{array}$ & 30.9 & 1.57 & 0.34 to 0.90 \\
\hline Men & 18.5 & 1.32 & -0.01 to 0.57 \\
\hline Women & 26.0 & 1.47 & 0.27 to 0.91 \\
\hline
\end{tabular}

\section{Key point}

Combined exposure to organisational downsizing and work related stress (model of effort reward imbalance) increases the probability of poor self reported health (work related symptoms) above and beyond additivity

ratios). For adjusted odds ratios, a minor decrease in synergy is seen.

\section{DISCUSSION}

The results of this cross sectional study based on a large sample of more than 20000 employed men and women indicate that a combined exposure to organisational downsizing and work related stress in terms of effort-reward imbalance is associated with an increased risk of work related symptoms that exceeds the risk produced by each exposure separately. Concerning the separate effects, effort-reward imbalance is more strongly associated with symptom load than organisational downsizing although the experience of downsizing net of work stress still produces significantly increased risks of symptom load.

To our knowledge, this is the first report examining the synergistic effect of two relevant exposures in modern working life, organisational downsizing and work stress, on a measure of self reported health, work related symptom load. Observed effects remain largely unchanged after extensive confounder control, and they show a comparable pattern in employed men and women. As far as the separate effects of the two exposures are concerned, findings are consistent with existing evidence. This finding is important in view of the fact that in a majority of investigations the health measures were more robust than is the case in this study.

Despite the relevance of this synergy effect, our study does not allow for further elucidation of possible mediating factors. For instance, downsizing reduces the probability that stable social support at work buffers adverse effects on health produced by work related stress. ${ }^{329}$ Alternatively, feelings of guilt and anger among survivors might act as powerful stressors, reducing employees' resources of coping with an additional stressor, an adverse work environment. ${ }^{30}$ A third possible interpretation concerns organisational justice. Several studies show that a low level of organisational justice is associated with reduced health. ${ }^{31}{ }^{32}$ It seems plausible that the experience of organisation downsizing reduces the sense of organisational justice among surviving employees.

The interpretation of results of this study is restricted by several methodological limitations. Firstly, this survey was not originally designed to test our main hypothesis. Rather, it served descriptive purposes, inviting researchers to use the dataset for secondary data analysis. Therefore, important variables of interest had to be defined by proxy measures. As far as downsizing is concerned, there is no indication that our index does not represent valid information although a more refined measure is desirable. For instance, the size of

\section{Policy implication}

As this combined exposure is associated with increased vulnerability, targeted worksite interventions in respective risk groups may be developed 
downsizing may moderate health effects. ${ }^{8}$ In our dataset, no information on size or timing of experienced downsizing during past two years was available.

Concerning the measurement of effort-reward imbalance at work, the test was restricted to the extrinsic component as no measure of overcommitment, a personal pattern of coping with work demands that moderates the health effects of imbalance, was available. While the psychometric properties of the two scales "effort" and "reward" were satisfactory, an important dimension of reward, job security, was not included in the respective scale. This decision was based on evidence that downsizing is closely associated with job insecurity. ${ }^{933}$ In an attempt to separate the effects of downsizing and work related stress as far as possible, we introduced job insecurity as a separate covariate into multivariate analysis. Thus, observed effects of effort-reward imbalance on symptom load may be underestimated rather than overestimated, given this restrictive measurement.

A further limitation is given by the cross sectional study design, in combination with the fact that predicting and criterion variables are based on self report data.

Therefore, observed associations are subject to reporting bias and may be influenced by specific personality characteristics, moods and contexts. ${ }^{34}{ }^{35}$ Yet, it should be pointed out that results of studies on work stress and health that controlled for factors such as negative affectivity or distinct personality traits were not abolished by these latter adjustments. $^{3637}$ Furthermore, cross sectional associations of self report measures of work stress and of downsizing with self report measures of health were replicated in the frame of prospective study designs, thus improving their validity. ${ }^{11}$

These limitations are balanced by several strengths of this study. Firstly, this investigation presents a systematic analysis of separate and combined effects of two important conditions of modern working life, organisational downsizing and work related stress, on health. Application of Rothman's synergy index allows for an estimate of the proportion of the observed effect size that is attributable to combined exposure rather than to additivity of the two separate effects. Secondly, this study introduced a theory based measure of long term work related stress, effort-reward imbalance. This model successfully predicted adverse health in a number of prospective and cross sectional studies in different occupational groups and countries and with regard to different health outcomes. ${ }^{16}{ }^{17}$

Thirdly, this report is based on a large sample representing a broad range of occupations that excludes only two types of occupations, self employed and civil servants. Whereas most studies on downsizing and health are derived from Scandinavian countries it is not known to what extent their findings can be generalised to other western European economies. This is one of the few reports testing the hypothesis with a large dataset on employed men and women in Germany. Finally, although our measure of work related symptom load has not been validated by medical examination it is known that symptom load is a strong predictor of sickness absence and disability pension, two core health indicators of companies. ${ }^{38} 39$

In policy terms, reported findings may support the implementation of specific measures of worksite health promotion in occupational groups characterised by double exposure to organisational downsizing and work related stress.

\section{ACKNOWLEDGEMENTS}

We thank the Federal Institute of Vocational Training and the Institute for Employment Research for supplying us with data, help, and advice.
Authors' affiliations

N Dragano, J Siegrist, Department of Medical Sociology, University of Duesseldorf, Duesseldorf, Germany

P E Verde, Coordination Centre for Clinical Trials, University Clinic Duesseldorf, and Department of Medical Sociology, Duesseldorf, Germany

Funding: none.

Conflicts of interest: none.

\section{REFERENCES}

1 Allen TD, Freeman DM, Russel JE. Survivor reactions to organizational downsizing: Does time ease the pain? J Occup Organ Psychol 2001;74:145-64.

2 Burke RL, Cooper CL. The organization in crisis. Oxford: Blackwell, 2000.

3 Kivimäki M, Vahtera J, Pentti J, et al. Factors underlying the effect of organisational downsizing on health of employees: a longitudinal cohort study. BMJ 2000;320:971-5

4 Vahtera J, Kivimaki M, Pentti J. Effect of organisational downsizing on health of employees. Lancet 1997;350:1124-8.

5 Westerlund $\mathbf{H}$, Ferrie J, Hagberg J, et al. Workplace expansion, long-term sickness absence, and hospital admission. Lancet 2004;363:1193-7.

6 Vahtera J, Kivimaki M, Pentti J, et al. Organizational downsizing, sickness absence, and mortality: 10-town prospective cohort study. BMJ 2004;328:555

7 Kivimaki M, Vahtera J, Ferrie JE, et al. Organisational downsizing and muskuloskeletal problems in employees: a prospective study. Occup Environ Med 2001;58:81 1-17.

8 Vahtera J, Kivimaki M, Forma $P$, et al. Organisational downsizing as a predictor of disability pension: the 10-town prospective cohort study. $J$ Epidemiol Community Health 2005;59:238-42.

9 Kivimäki M, Vahtera J, Pentti J, et al. Downsizing, changes in work, and selfrated health of employees: a 7-year 3-wave panel study. Anxiety Stress Coping 2001; 14:59-73.

10 Grunberg L, Moore S, Greenberg E. Differences in psychological and physical health among layoff survivors: the effect of layoff contact. $J$ Occup Health Psychol 2001;6:15-25.

11 Moore S, Grunberg L, Greenberg E. Repeated downsizing contact: the effects of similar and dissimilar layoff experiences on work and well-being outcomes. J Occup Health Psychol 2004;9:247-57.

12 Hertting A, Nilsson K, Theorell T, et al. Downsizing and reorganization: demands, challenges and ambiguity for registered nurses. J Adv Nurs 2004; 45: 145-54.

13 Shannon HS, Woodward CA, Cunningham CE, et al. Changes in general health and musculoskeletal outcomes in the workforce of a hospital undergoing rapid change: a longitudinal study. J Occup Health Psychol $2001 ; 6: 3-14$.

14 Westerlund H, Theorell T, Alfredsson L. Organizational instability and cardiovascular risk factors in white-collar employees. Eur J Public Health 2004; 14:37-42.

15 Siegrist J, Starke D, Chandola T, et al. The measurement of effort-reward imbalance at work: European comparisons. Soc Sci Med 2004;58: 1483-99.

16 Tsutsumi A, Kawakami N. A review of empirical studies on the model of effortreward imbalance at work: reducing occupational stress by implementing a new theory. Soc Sci Med 2004;59:2335-9.

17 van Vegchel $\mathrm{N}$, de Jonge J, Bosma $\mathrm{H}$, et al. Reviewing the effort-reward imbalance model: drawing up the balance of 45 empirical studies. Soc Sci Med 2005:60:1117-31.

18 Dostal W, Jansen R, Parmentier K. Wandel der Erwerbsarbeit: Arbeitssituation, Informatisierung, berufliche Mobilität und Weiterbildung. Berlin: Institut für Arbeitsmarkt- und Berufsforschung, 2000.

19 Rothman KJ. Modern epidemiology. Boston: Little, Brown, 1986.

20 Hallqvist J, Diderichsen F, Theorell T, et al. Is the effect of job strain on myocardial infarction risk due to interaction between high psychological demands and low decision latituede? Results from Stockholm heart epidemiology program (SHEEP). Soc Sci Med 1998:46:1405-15.

21 Fahrenberg J. Somatic complaints in the German population. J Psychosom Res 1995;39:809-17.

22 Franke G. The Derogatis symptom-checklist. (German version). Weinheim: Beltz, 1995.

23 von Zerssen D, Koeller DM. Die Beschwerden-Liste. (Manual in German). Weinheim: Beltz-Verlag, 1976

24 Unesco. International standard classification of education, ISCED 1997. Paris: Unesco, 1997.

25 Östlin P. Gender inequalities in health: the significance of work. In: Wamala SP, Lynch J, eds. Gender and social inequities in health. Lund: Studentlitteratur, 2002:43-65.

26 Weidner G, Cain VS. The gender gap in heart disease: lessons from Eastern Europe. Am J Public Health 2003:93:768-70.

27 Hosmer DW, Lemeshow S. Confidence interval estimation of interaction. Epidemiology 1992;3:452-6.

28 Skrondal A. Interaction as departure from additivity in case-control studies: a cautionary note. Am J Public Health 2003;158:251-8.

29 Swanson V, Power K. Employees perception of organizational restructuring: the role of social support. Work and Stress 2001;15:161-78.

30 Noer D. Layoff survivor sickness: What it is and what to do about it. In: Gowing MK, Kraft JD, Quick JC, eds. The new organizational reality. 
Downsizing, restructuring, and revitalization. Washington: American Psychological Association, 1998:207-20.

31 Brockner J, Greenberg J. The impact of layoffs on survivors: an organizational justice perspective. In: Carroll JS, ed. Applied social psychology and organizational settings. Hillsdale: Lawrence Erlbaum Associates, 1990:45-75.

32 Mishra AK, Spreitzer GM. Explaining how survivors respond to downsizing: the roles of trust, empowerment, justice and work redesign. Acad Manage Rev 1998;23:567-88

33 Benach J, Amable M, Muntaner C, et al. The consequences of flexible work for health: are we looking at the right place. J Epidemiol Community Health 2002;56:405-6.

34 Kahneman D, Diener E, Schwarz N. Well being: the foundations of hedonic psychology. New York: Russel Sage Foundations, 1999.
35 Spector PE, Zapf D, Chen PY, et al. Why negative affectivity should not be controlled in job stress research: don't throw out the baby with the bath water. J Organ Behav 2000;21:79-95.

36 Bosma H, Peter R, Siegrist J, et al. Two alternative job stress models and the risk of coronary heart disease. Am J Public Health 1998;88:68-74.

37 Stansfeld SA, Fuhrer R, Shipley MJ, et al. Work characteristics predict psychiatric disorder: prospective results from the Whitehall II study. Occup Environ Med 1999;56:302-7.

38 Ferrie JE, Head J, Shipley MJ, et al. A comparison of self-reported sickness absence with absences recorded in employers' registers: evidence from the Whitehall II study. Occup Environ Med 2005;62:74-9.

39 Karpansalo M, Manninen P, Kauhanen J, et al. Perceived health as a predictor of early retirement. Scand J Work Environ Health 2004;30:287-92. 